\title{
Indigenous early career researchers: creating pearls in the academy
}

\author{
Michelle Lea Locke ${ }^{1}$ (D) $\cdot$ Michelle Trudgett ${ }^{2}$ (D) $\cdot$ Susan Page ${ }^{2}$ (D)
}

Received: 10 May 2021 / Accepted: 13 September 2021/ Published online: 29 October 2021

(c) The Australian Association for Research in Education, Inc. 2021

\begin{abstract}
This paper provides a snapshot of Indigenous Early Career Researchers in Australia derived from demographic information collected in the first stage of the 'Developing Indigenous Early Career Researchers' project. Analysis of the data to date has evidenced much diversity across this cohort. However, one commonality across all Indigenous Early Career Researchers was a commitment to the value and validity of Indigenous Ways of Knowing in the higher education sector. With the use of Tribal Critical Race Theory this paper explores the ways in which Indigenous Early Career Researchers disrupt Western-based academies and schools of thought and proposes that Indigenous Early Carer Researchers grow 'pearls' of experience and knowledge within the higher education sector that are essential to the development of a richer academy and stronger Indigenous communities.
\end{abstract}

Keywords Indigenous · Early career researcher $\cdot$ Higher education $\cdot$ Pearls

\section{Introduction}

In Australia, academic scholars that are within the first 5 years of receiving a doctoral award are classified as early career researchers (ECRs) (Bazeley, 2003). This timeframe is set in accordance with funding rules provided by the Australian Research Council (ARC) and has been identified as a crucial period in which an ECR builds their career trajectory towards recognition as an independent researcher (Bazeley, 2010; Laudel \& Gläser, 2008).

In response to the recognised importance of this stage, a growing body of literature in Australia and abroad has sought to identify ways in which to support nonIndigenous ECRs (Browning et al., 2014; Crome et al., 2019; Sawarkar et al., 2019).

Michelle Lea Locke

M.Locke@westernsydney.edu.au

1 Western Sydney University, Second Ave, Kingswood, NSW 2747, Australia

2 Western Sydney University, Parramatta South Campus, Victoria Rd, Rydalmere, NSW 2116, Australia 
In contrast, research investigating the development of Indigenous ECRs is severely lacking (Hutchings et al., 2019; Moodie et al., 2018). This is of significant concern as emerging Australian and international research has provided evidence that Indigenous, First Nations and Faculty of colour ${ }^{1}$ academics face additional challenges and stresses to those experienced by their non-Indigenous colleagues (Fredericks, 2011; Gaudry \& Lorenz, 2018; Joseph \& Hirshfield, 2011; Nakata, 2006; Page \& Asmar, 2008; Thunig \& Jones, 2020). With this understanding it is clear that research which specifically investigates the experiences of Australian Indigenous ECRs is timely.

The 'Developing Indigenous Early Career Researchers' project is a three-year longitudinal study, funded by the Australian Research Council (ARC) which aims to address this gap in the research. This paper firstly explores demographic information collected in the first year of the project (stage one) and provides a snapshot of the vast diversity of Indigenous ECRs in regard to experience and employment conditions in the higher education sector across Australia. Specific aspects explored in this paper include broad institutional and Indigenous Country representation, participant age range, time employed in the higher education sector, stage/year in the early career phase, current employment, and workload allocations for research, teaching and service/community tasks. Secondly, the question, 'what do Indigenous ECRs bring to the academy?' is addressed in acknowledgement of both the diversity and a point of commonality that was expressed by all Indigenous ECRs. Despite the fact that the participating Indigenous ECRs are employed in different Institutions across Australia and are on differing research trajectories, this study notes a common commitment from Indigenous ECRs, participating in this project, to affecting change both within the academy and in the Indigenous communities in which they are connected and/or work. Using Tribal Critical Race Theory (TribalCrit) (Brayboy, 2005) this paper positions Indigenous ECRs as the agitators who action change and growth as with the creation of a pearl within an oyster shell. The Western academy can be considered as the oyster shell in which both Western and Indigenous Knowledges can interact to create diverse curriculums, new research approaches and methodologies.

\section{Literature review}

In Australia the 'Review of Higher Education Access and Outcomes for Aboriginal and Torres Strait Islander People Report' (Behrendt et al., 2012) noted that building a research pipeline of Indigenous Higher Degree Research (HDR) students and Indigenous ECRs is paramount to growing the number of successful Indigenous HDR students and Indigenous academics (Behrendt et al., 2012). However, 6 years after this report, growth in Indigenous postgraduate enrolments was largely hindered by low rates of completion. Specifically, Indigenous postgraduate completion rates represented less than $1 \%$ ( $0.84 \%$ or 54 completions) of all domestic postgraduate

\footnotetext{
${ }^{1}$ In the UK, US and Canada the term 'faculty of colour' has been used to represent non-white academics.
} 
research completions (Universities Australia, 2020). There was minimal growth in the employment of Indigenous academic staff from $0.73 \%$ in 2005 to $0.92 \%$ in 2018. This was in conjunction with an increase in teaching only roles for Indigenous academics, from 5.6\% in 2005 to $14.1 \%$ in 2018 (Universities Australia, 2020). This greatly impedes the aforementioned goal to build on the research capacity of Indigenous HDRs and ECRs.

Research in the UK, Australia, and New Zealand (Adcroft \& Taylor, 2013; Page \& Asmar, 2008; Sutherland, 2017) has shown that the roles and responsibilities associated with teaching inhibit ECR trajectories due to the demand on time and low currency towards establishing a research career. In addition, Page and Asmar (2008) have shown that for Indigenous academics teaching responsibilities are additionally burdened with the provision of high levels of support to Indigenous and non-Indigenous students and staff. Research in Australia, the United States and Canada (Asmar \& Page, 2009; June, 2015; Mohamed \& Beagan, 2019) has shown that Indigenous, First Nations and faculty of colour academics often incur additional institutional demands as a result of their Indigeneity.

International research has raised concerns for Indigenous and faculty of colour academics who are routinely tasked to Indigenise curriculums, teach Indigenous specific units and to sit on committees in order that the institution meets its obligations to engaging Indigenous perspectives (Gaudry \& Lorenz, 2018; Joseph \& Hirshfield, 2011). Identified as cultural taxation, Joseph and Hirshfield (2011) also noted that 'faculty of colour experience cultural taxation in the form of unequal expectations, being overcommitted, coping with colleagues' problematic behaviours and having to prove they are academically qualified' (p. 136).

Whilst there is an emerging body of literature on the experiences and barriers faced by First Nations ECRs and faculty of colour academics (Asmar \& Page, 2009, 2018; Henry et al., 2017; Joseph \& Hirshfield, 2011; Staniland et al., 2019) research into the specific experiences of Indigenous ECRs is severely lacking (Hutchings et al., 2019; Moodie et al., 2018). Thus, with a national commitment, 'to advance Aboriginal and Torres Strait Islander participation and success in higher education' (Universities Australia, 2020) it is timely that the experiences and needs of Indigenous ECRs are investigated and understood.

\section{Methodology and methods}

A longitudinal approach has been taken to facilitate the exploration of an 'evolving and complex processes' (Murray et al., 2009). As well, the longitudinal nature of this project will facilitate careful identification of the developmental trajectories (including enablers and barriers) to the careers of Indigenous ECRs and enable us to establish more trustful research relationships with the participants. This paper reports on findings from the first-year interviews. Using a qualitative methods approach (Denzin et al., 2018) Indigenous ECRs were invited to share their stories (Bessarab \& Ng'andu, 2010) and experiences in semi-structured interviews. The research was conducted by three Indigenous scholars, comprising of two Professors (authors two and three) and an Indigenous Early Career Researcher who joined the 
project on completion of their doctoral program (author one). It is recognised that author one's position in this project as an Indigenous ECR provides the research team with a direct connection to the research topic.

Stemming from implications associated with the Covid-19 pandemic, physical distancing restrictions necessitated that all 2020 interviews were conducted online via secure and purposely scheduled meetings on the video conferencing service, 'zoom'. Thirty Indigenous ECRs took part in stage 1 of this project and it is intended that all thirty will be reinterviewed in stages two and three. In most cases, ECRs logged into the zoom interview from home offices which likely increased their level of comfort in sharing their thoughts and experiences, due to being in private and comfortable locations as opposed to being in a potentially shared space in an institution founded on and grounded in Western Worldviews and value systems (Martin, 2008; Povey \& Trudgett, 2019; Rigney, 2001).

\section{Data analysis}

All interviews were voice recorded and transcribed by a professional transcription service. Once the Indigenous ECR approved their transcript it was uploaded into qualitative data analysis computer software package NVivo 12. The software provided a tool to identify and compare participant demographic attributes. Themes from Indigenous ECR stories and experiences were categorised and analysed with the use of the NVivo 12 'create' and 'explore' functions that allow the researcher to examine the data in depth and from a variety of viewpoints (Jackson \& Bazeley, 2019). Data for this paper was firstly drawn from demographic information supplied by the participants and secondly from two different themes that were identified as occurring in the majority of recorded interviews. Deep analysis with the use of Tribal Critical Race Theory (TribalCrit) Theory of the data provides a window into the way in which participants position themselves (Silverman, 2013) as Indigenous ECRs in the academy and as representatives of the Aboriginal and Torres Strait Islander communities in which they are connected and/or work.

\section{Theoretical framework}

Critical Race Theory (CRT) purports that racism is normal or endemic in society and people who are members of the dominant society often fail to see its existence (Delgado \& Stefancic, 1992). Therefore, the application of critical race theory in education is to expose racism in its wide and varied incarnations (Ladson-Billings, 1998). Brayboy (2005) argued that as CRT grew from the Civil Rights actions of African American peoples it only addresses race issues from a 'black-white' binary and as such it inhibits participation and inclusion of other ethic/racial minorities. Specifically, he identified that American Indians experience racism differently to African Americans as their experiences are directly related to colonisation. As a result Brayboy (2005) developed Tribal Critical Race Theory (TribalCrit) which changes the main tenet of CRT, 'racism is endemic in society' to a more nuanced approach that recognises the unique characteristics of First Nations/Tribal peoples to 
state that, 'colonization is endemic to society'. TribalCrit is built on nine tenets that identify and address racial inequities experienced specifically by colonised peoples. In the second part of this paper, the fifth tenet of TribalCrit is employed to present ways in which Indigenous ECRs contribute to the academy.

The fifth tenant of TribalCrit is that, 'the concept of culture, knowledge, and power take on new meaning when examined through an Indigenous lens' (Brayboy, 2005). In applying this tenet to Indigenous ECRs employed in Western-based institutions we explore the interactions between Indigenous and non-Indigenous knowledges in the academy. In offering an Australian Indigenous perspective Moodie (2018) likens this tenet to Nakata (2006) Cultural Interface and the formation of Indigenous standpoints and perspectives. From this perspective Indigenous ECRs are positioned as agents of change, in which 'attention to the cultural interface describes the position from which we interrogate the complexities of power and resist imposed positioning' (Moodie, 2018, p.40). Thus, in conducting Indigenous research and coordinating Indigenous course units from an Indigenous standpoint, Indigenous ECRs challenge knowledge produced by non-Indigenous scholars, about Indigenous peoples in Western academies.

\section{Recruitment}

As there are no publicly accessible lists that identify those Indigenous Australians with a doctoral qualification (Trudgett et al., 2016) a number of recruitment methods were used to identify and locate Indigenous ECRs. Firstly, the researchers utilised their own professional contacts and networks to develop a list of potential participants. Secondly, a post on Twitter provided a brief explanation of the research and an email contact for any Indigenous ECRs that might be interested in participating. Finally, a review of past and current ARC Discovery Indigenous grants, and a search in Trove for Indigenous thesis published in the last 5 years, added a number of potential Indigenous ECRs to the list. A total of 58 potential participants were sent information and an invitation to participate using email contacts sourced through institution directories, LinkedIn, ORCID, and Twitter.

\section{Indigenous early career researcher participants}

Of the 58 potential participants contacted, a total of 36 responded to emailed invitations, including two who expressed their interest in the project but an inability to participate due to family and professional demands. Initially, the total number of Indigenous ECRs who agreed to participate was 34; however, four Indigenous ECRs withdrew before their first interview due to work and/or family commitments. Thus, a total of 30 Indigenous ECRs participated in online (zoom) interviews to share their stories and experiences of their ECR journey so far.

The use of pseudonyms was encouraged as the risk of identification for Indigenous ECRs is high due to the small overall cohort. This risk could be increased if the use of pseudonyms was not consistent across all Indigenous ECRs participating in the Developing Indigenous Early Career Researchers project. Whilst this is not 
an extensive cohort of Indigenous ECRs it has provided a sound snapshot of the diverse and varied demographical characteristics of Indigenous ECRs from a variety of higher education institutions across Australia. Specifically, our Indigenous ECRs represent at least 35 different Aboriginal and Torres Strait Islander Nations, (as some participants had connections to more than one Indigenous Nation) and were employed in 21 different institutions across six out of eight States/Territories of Australia. Likewise, their Doctoral Degrees were awarded in 19 different institutions across six States/Territories (different to employment States/Territories) and one internationally.

\section{Findings}

In this paper the findings are presented as two separate sections. Firstly, the level of diversity among our Indigenous ECR participants is explored through the examination of demographic data. Whilst remaining mindful of the vast diversity of Indigenous ECRs participating in this study the second part of our findings brings to light the self-identified contributions of Indigenous ECRs to the academy.

\section{Demographic characteristics of Indigenous early career researchers}

To support the development of Indigenous ECRs it is necessary to gain an understanding of who they are and identify specific characteristics that influence career development and trajectories. Demographic data shared by thirty Indigenous ECRs has been recorded and grouped under four main headings for analysis. Firstly, conditions specific to $\mathrm{PhD}$ conferral are presented, which includes the years in which Doctoral Degrees were awarded, duration and mode of study, and whether or not the early career researcher is employed in the same institution that their $\mathrm{PhD}$ was conferred. Secondly, as ECRs are deemed to be within the first 5 years of attaining a $\mathrm{PhD}$, the age and the participants early career researcher year/stage was explored. Thirdly, a brief reflection of Indigenous early career researcher understanding and confidence in the academy was considered in regard to the number of years they had been employed in the Higher Education sector. Finally, early career researcher employment levels, positions and workload allocations for research, teaching and service/community are compared and contrasted to gain a clearer picture of the roles and responsibilities these Indigenous ECRs are engaged in.

\section{Indigenous PhD candidate to Indigenous early career researcher}

In our study, 30 Indigenous ECRs received PhD conferrals from December 2015 to October 2020. Of this cohort 3\% had their degrees conferred in 2015, $10 \%$ in 2016, $17 \%$ in $2017,27 \%$ in $2018,40 \%$ in 2019 and final $3 \%$ in 2020 . Thus, 2019 had the highest number of degrees conferred whilst 2015 and 2020 had the lowest. Indigenous $\mathrm{PhD}$ completions in this specified time frame are strictly reflective of this 
particular cohort and can in no way be seen as indicative of the broader Indigenous early career researcher community due to the limited sample.

The mode in which Indigenous ECRs engaged in their PhD was spread relatively evenly between full-time, part-time and those who engaged in a combination of both part-time and full-time. Just under a quarter of Indigenous ECRs completed their PhD's in 4 years, with $17 \%$ completing in 3.5 years and a further $17 \%$ completing in 7 years. The shortest timeframe for completion was less than 3 years and the longest was over 7 years. Completion times were affected by the mode of study as well as other contributing factors such as family responsibilities, employment and health.

Of particular interest is the fact that just over half (53\%) of our Indigenous ECRs were employed at the same institution in which they completed their $\mathrm{PhD}$. This factor warrants further investigation to determine whether it was a deliberate choice on the part of the Indigenous early career researcher to be closer to home or alternatively an institutional factor that was out of the Indigenous early career researcher's control.

Relatedly, research reveals that a growth in the number of doctoral completions (Bazeley, 2003; Crome et al., 2019) has increased competition for tenured positions (Scaffidi \& Berman, 2011) and that an increase in the casualisation of academic employment impacts postdoctoral employment opportunities and job security generally (Klopper \& Power, 2014; Robertson \& Fyffe, 2019). In the wake of the push to address the lack of Indigenous staff in the academy (Behrendt et al., 2012; Trudgett, 2011) this is of particular concern for the development of sound Indigenous early career researcher career trajectories and future job security.

\section{Indigenous early career researcher age}

Aside from nine participants who chose not to disclose their age there was an even spread of Indigenous ECRs between the ages of 30-39 (6 ECRs) and 40-49 (6 ECRs) years. There was a slightly higher number of Indigenous ECRs in the 50-59 (7 ECRS) years bracket and a significant drop for participants aged between 60 and 69 years old (2 ECRS). This drop in numbers is in alignment with the age pension legislation (Department of Social Services, 2019) which changed from 66 to 66 years and 6 months from the first July 2021. However, it is not necessarily reflective of the average age of retirement in Australia, which is 55.4 years (Australian Bureau of Statistics, 2020). Interestingly, the age of an Indigenous early career researcher did not necessarily dictate the number of years they had been an early career researcher. For instance, there was an equal number of first year ECRs across three different age brackets, 30-39, 40-49 and 50-59 years old. This is of particular concern for Indigenous ECRs currently in the 50-59-year age bracket, as they are likely to be at retirement age before moving out of the perceived apprentice stage (Laudel \& Gläser, 2008). This finding is also indicative of research in New Zealand which noted that the average age of a Māori $\mathrm{PhD}$ candidate was 49 (Nana et al., 2010). Thus, the longevity of an academic career and the ability to build a larger pool of Māori academics available to act as mentors for up and coming Māori higher degree researchers and ECRs is severely limited (Kidman \& Chu, 2017). 


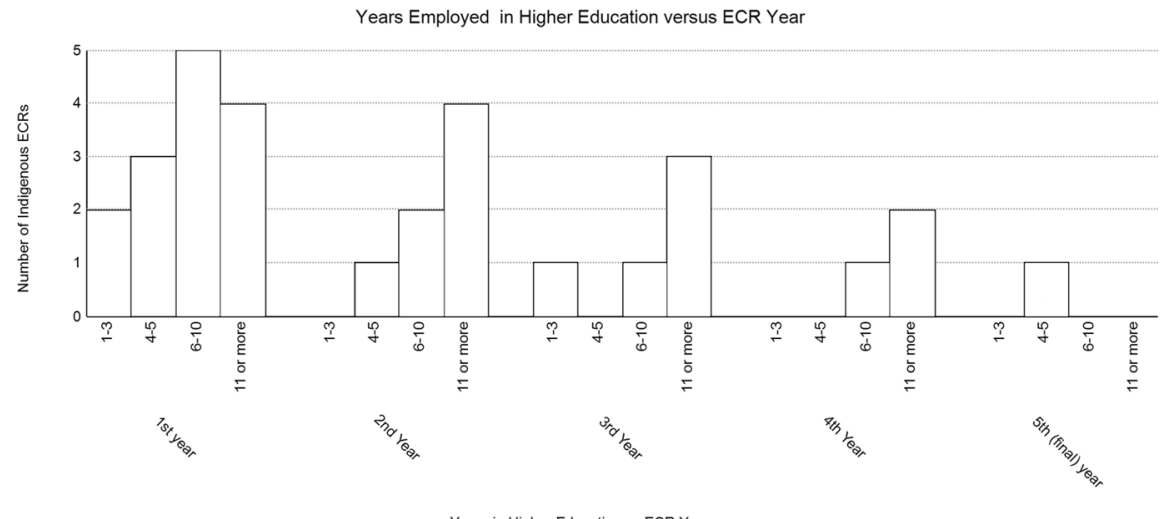

Fig. 1 Comparison of the number of years Indigenous ECRs were employed in the higher education sector versus ECR Year

\section{Employment in higher education}

Of the Indigenous ECRs participating in this study just under half (43\%) have been employed in the higher education sector for at least 11 years and a further $30 \%$ were employed from six to ten years. It is clear from Fig. 1 that the number of years employed in the higher education sector is not comparable to the ECR year. In this project, there are first year ECRs who have been employed in the higher education sector for one year and others for more than 11 years. Comparatively, there are first, third and fifth year Indigenous ECRs who have only been employed in the higher education sector from one to a maximum of 3 years.

Although approximately, $63 \%$ of this cohort have been working in the higher education sector for a minimum of 6 years, it cannot be assumed that the same number feel well versed, confidant and/or in control of their current roles and responsibilities as Indigenous ECRs in the academy. In addition to differences in the number of years in higher education and the ECR year, diversity among Indigenous ECRs was also evident across employment conditions and roles. For example, the mode (fulltime, part time or casual), level, position and even faculty of employment varied greatly and Indigenous ECRs identified a variety of needs for support and/or guidance across these varied roles and responsibilities. Stated needs for support and/or mentoring included, understanding internal institutional structures, developing and coordinating course units, grant writing, publishing and mapping an effective career pathway. Some Indigenous ECRs also stated a specific desire for an Indigenous academic/research mentor, who not only understands the system but also the unique challenges that Indigenous ECRs face in the academy. The important take away is the vast diversity of engagement, experiences and identified needs of this pool of Indigenous ECRs. 
Table 1 Number of Indigenous ECRs at each level of employment

\begin{tabular}{lc}
\hline Employment level & $\begin{array}{l}\text { No. Indigenous ECRs } \\
\text { employed at this level }\end{array}$ \\
\hline Academic Level A & 1 \\
Academic Level B & 17 \\
Academic Level C & 9 \\
Academic Level D & 2 \\
Academic Level E & 1 \\
Senior Administrators & 1 \\
Total & 31 \\
\hline
\end{tabular}

\section{Indigenous early career researcher employment levels, positions and workload allocation}

Significant diversity also exists in the level and position titles in which this ECR cohort are employed. Interestingly, this cohort of Indigenous ECRs named 17 different position titles. Whilst there were similarities in the names of positions, the position titles quite often included a specific faculty, school or fellowship name which then distinguished the role from other matching positions.

In addition, Indigenous ECRs participating in this study are employed under two different awards (academic and professional). In the case of academic levels Indigenous ECRs are represented in all levels from A to E. However, unsurprisingly, the majority (84.3\%) are employed at either Academic Level B or C, with just over half (53.13\%) holding positions at Academic Level B. The remaining $15.6 \%$ are spread almost evenly across a number of other academic and professional awards. Perhaps less expected is that a small number of the ECRs were in quite senior roles.

Table 1 shows that the employment levels of this Indigenous ECR cohort is especially wide ranging. In addition, it should be noted that while there are 30 Indigenous ECRs participating in this project, the total number of levels is 31 . This is due to the fact that two Indigenous ECRs reported fulltime employment in dual positions which combine two different roles. For one of these participants both positions fall under the same employment level while the two positions held by the second participant fall into different employment levels. This, of course adds another level of complexity and diversity to Indigenous ECR employment possibilities.

In association with the employment level of an Indigenous ECR are the associated roles and responsibilities that have the potential to support or hinder a research career trajectory. Whilst workload allocation is examined in more detail below, research has shown that many ECRs are encumbered with teaching loads that often inhibit an ECRs ability to conduct research and produce publications, which are of more importance to career progression (Adcroft \& Taylor, 2013). This position was also raised in an Australian study which noted that the roles and responsibilities associated with teaching are hardly beneficial to the establishment of a sound research career trajectory. 'High levels of teaching/support rarely count in terms of promotion, and also divert time from the sort of achievements that will count-like publications' (Page \& Asmar, 2008, p. 115). It is 
important to note, however; that the allocation of teaching is not reserved for Lecturer positions only. All positions can potentially be allocated a teaching role, and in this cohort that includes Senior Research Fellows, although the percentage of time allocated to teaching is more likely (but not always) lower in lieu of a higher research load. Thus, challenges associated with the time demands of teaching roles is a cause for concern in career development of Senior Research Fellows, Post-Doctoral Research Fellows, Post-Doctoral Fellows, Project Officer/Leaders, Senior Lecturers and Lecturers.

In regard to teaching responsibilities, Indigenous ECRs participating in this project can be assigned to one of two groups, those with an allocated research, teaching and service/community workload and those without. Of the seven Indigenous ECRs who are not assigned specific workloads for research, teaching and service/community; three hold senior positions, three are employed as casual teachers and one is employed in a dual role. Thus 77\% (23 Indigenous ECRs) are allocated research, teaching and service/community workloads.

Surprisingly, there are ten different workload allocations for only 23 Indigenous ECRs. The most common workload allocation was 40\% Research: 40\% Teaching and $20 \%$ Service/Community. This was reported by 11 out of 23 Indigenous ECRs, which is slightly under half the number of Indigenous ECRs with workload allocations. Of the remaining 12 Indigenous ECRs nine different workload allocations were recorded, demonstrating significant inconsistencies in regard to the research, teaching and service/community expectations of this Indigenous ECR cohort. Remembering that these Indigenous ECRs are in a critical period where development of research track records is usually considered vital for career progress (Bazeley, 2003; Browning et al., 2014; Crome et al., 2019) it is worth noting that five have teaching loads of $50 \%$ or more. In addition, only seven out of 23 Indigenous ECRs are assigned workloads that prioritise research over teaching. Specifically, 16 out of 23 Indigenous ECRs have workloads that assign teaching with an equivalent if not higher workload provision than that of research.

Corresponding analysis of the interview data also shows that Indigenous ECRs reported a number of concerns in regard to workload allocations. While this will be explored in greater detail in another paper, the variance of workload allocations across this Indigenous ECR cohort was demonstrated by the fact that the most common workload ratio of 40:40:20 was evident in three different positions and across two different employment levels. In addition, there are also examples where positions with the same title and employment level have quite different workload allocations. In addition, Indigenous ECRs reflected on the inaccuracy of prescribed allocations, including some who felt that they were held to account and/or were unsuccessful in gaining a promotion as a result of unrealistic measures that fail to record or recognise real time demands and constraints. Overall, teaching and service/community roles were frequently reported to be underestimated and, in some cases undervalued, which raises important questions as to the accuracy and relevance of workload allocations.

It is clear from the demographic data explored in this paper that Indigenous ECRs and the positions they hold are anything but uniform. Such multiplicity of demographic characteristics regarding age, higher education experience, employment 
levels, positions and workload allocations contributes further to an already diverse group of academics that hail from a range of Indigenous Nations and Higher Education institutions across Australia.

\section{Indigenous early career researchers contributions to the academy}

Despite the many differences that shape and impact the career focus and trajectory of the Indigenous ECRs participating in this study there also exists an underlying commonality derived from Indigenous worldviews, that exposes a shared commitment to affecting positive change for Indigenous peoples both within the academy and in the Indigenous communities in which they are connected and/or work. From the shared perspectives and experiences of Indigenous ECRs, in this section of the findings we explore self-identified contributions that Indigenous ECRs bring to the academy. Specifically, Indigenous ECRs position themselves as capable and knowledgeable agents of change due to their varied skills and knowledges, their understanding of the need to collaborate with others, including Indigenous communities and their commitment to effecting change for Indigenous people in the academy and society in general.

\section{Specialised skills and knowledges}

Indigenous ECRs identified specific skills and/or knowledges that they can bring to the spaces in which they are engaged. For example, several Indigenous ECRs have extensive experience with Indigenous peoples outside the academy in professional fields such as the arts, design, health, and business. Each of these Indigenous ECRs noted the value of their level of industry experience and ways in which their skills could be utilised for the benefit of both Indigenous and non-Indigenous students and staff. Julie noted that she has been able to introduce creativity to the research space as a result of her past employment experiences. Whilst Cooper spoke specifically of bringing Aboriginal research practices into the academy.

I always think Aboriginal people kind of got to do things two ways. They've got to do it the conventional way and then we do it the community way, then we've got to master the way that it has to be done. It's how I did my PhD.

Likewise, Mica shared her understanding of Indigenous research and knowledges and expressed some frustration at the way in which academics separate and/or isolate themselves in different disciplines. 'I see Indigenous research and Indigenous studies as being very interdisciplinary. I think we've fallen into the place of, 'oh well I' $m$ in this discipline or I'm in that discipline.' That's not really how Indigenous knowledges work.

\section{Collaboration with Indigenous academics and community}

The importance and values of working collaboratively with others and particularly of including Indigenous community was specifically expressed by all Indigenous 
ECRs in the study. One participant emphasised that while she is confidant in meeting institutional requirements, she is aware that her inability to collaborate with other Indigenous academics restricts her ability to honour important cultural protocols and/or participate in research that is respectful and of benefit to the Traditional custodians.

How do I critique and make sure that I'm on point? Because I'm only one Indigenous person, I'm one. I'm not even a [traditional custodian], so it's not even my own Country to be making assertions on. (Lee)

The need to collaborate and network with Indigenous academics and Indigenous community members was repeatedly raised by Indigenous ECRs. This was not only in relation to producing culturally appropriate research that built on the individual's career trajectory but also as a means to create opportunities and pathways for other Indigenous students and peers.

\section{Effecting change}

More often than not Indigenous ECRs considered their roles and achievements in the academy as valuable to effecting change for Indigenous peoples rather than as attaining individual recognition or awards. Although Indigenous ECRs discussed and identified a variety of challenges and barriers to their individual progression within the academy the overwhelming motivation and aspiration of the Indigenous ECRs participating in this study was community focussed.

For me that's - it's about creating space, making space in higher education for Indigenous people. That's my goal. (Sasha)

Thus, ways in which Indigenous ECRs contribute to the academy should not be measured from a Western world view of individual academic advancement but from an Indigenous worldview that recognises relatedness and accountability in Indigenous ways of knowing, being and doing (Martin \& Mirraboopa, 2003).

\section{Discussion}

It is imperative that Indigenous ECRs, such as those in this project are recognised as capable and competent agents of change. Certainly, Battiste (2005 p, 1) advocates this as the role of Indigenous academics.

The task for Indigenous academics has been to affirm and activate the holistic paradigm of Indigenous knowledge to reveal the wealth and richness of Indigenous languages, worldviews, teachings and experiences, all of which have been systematically excluded from contemporary educational institutions and from Euroentric knowledge systems.

Although, it is critical to note that this positioning of Indigenous ECRs is not at all intended to eliminate responsibility of all educators, scholars and the higher 
education sector itself to addressing social and educational disparities between Indigenous and non-Indigenous Australians. Rather that, the presence of Indigenous ECRs brings Indigenous standpoints (Nakata, 2006) into the academy which then promotes resistance and works to alleviate the domination of Western-based knowledges.

The exercise of these various forms of knowledge is always context-specific and the different forms must be integrated with one another in order to achieve successful resistance and, thus survival. For example, knowledge learned in school can be used in conjunction with tribal knowledge towards social justice (Brayboy, 2005, p. 435).

Metaphorically, Western knowledge could be considered as an oyster within the 'shell' of the Western academy and Indigenous knowledges as a grain of sand. Although they remain independent of one another, interactions between the two are capable of creating a pearl. Course units and research projects designed and led by Indigenous ECRs bring Indigenous Ways of knowing and doing into a Western dominated space and acts to challenge racialising discourses and white settler constructions of Indigeneity (Brayboy, 2005; Moodie, 2018).

However, it is true that in order for the pearl to grow there must be a combination of commonality (shared space inside the oyster shell) and difference (an oyster and the grain of sand). Brayboy (2005) explains that Tribal Critical Race Theory (TribalCrit) is grounded in the commonalities that exist between Indigenous ontologies and epistemologies whilst also recognising difference between communities and individuals. This is of relevance to this study from two perspectives. Firstly, if Indigenous knowledge is represented as a grain of sand we must also recognise that each grain of sand is an integral part of the Country to which it belongs. Thus each grain of sand brings Country and hence Indigenous ways of knowing to the oyster (Western knowledges) and through this interaction new knowledges and approaches to education and research (pearls) can grow. Pearls like knowledges are all different, as their individual characteristics are determined by the entities in the environment in which they grow. A singular pearl is a unique and valuable creation that can increase in value and purpose when strung together with others. Thus this paper positions the academy as a common space, an oyster shell in which Indigenous and non-Indigenous worldviews can interact and in doing so shape and develop new knowledges, approaches and methodologies (pearls) that enrich and strengthen the academy and in turn the communities engaged with it.

\section{Conclusion}

In this paper the creation of a pearl is used as a metaphor for the development of diverse curriculums, new research approaches, methodologies and an overall greater diversity in decision making and strategy in the higher education sector. Importantly, Indigenous ECRs are recognised as vital and capable agents that bring Indigenous ways of knowing into Western-based institutions. Certainly, the vast diversity of skills, experience and connections in the academy and in communities is a testament 
to this. Like a grain of sand inside an oyster shell Indigenous ECRs bring Indigenous knowledges and perspectives that are capable of agitating the academy from within. Course units and research projects designed and led by Indigenous ECRs challenge racialising discourses and white settler constructions of Indigeneity and in doing so can affect positive change and the growth of a richer academy and stronger Indigenous communities. It is the responsibility of every institution to nurture and develop the current and future generations of Indigenous ECRs.

Funding This project is funded by the Australian Research Council.

\section{Declarations}

Conflicts of interest The authors declare that they have no conflict of interests.

Ethics approval This study has been approved by the Western Sydney University Human Research Ethics Committee. The Approval number is H13270.

Consent to participate The text below was taken directly from the Participant Consent Form for the Developing Indigenous Early Career Researchers ARC Project.

\section{References}

Adcroft, A., \& Taylor, D. (2013). Support for new career academics: An integrated model for research intensive university business and management schools. Studies in Higher Education, 38(6), 827840. https://doi.org/10.1080/03075079.2011.599378

Asmar, C., \& Page, S. (2009). Sources of satisfaction and stress among Indigenous academic teachers: Findings from a national Australian study. Asia Pacific Journal of Education, 29(3), 387-401. https://doi.org/10.1080/02188790903097505

Asmar, C., \& Page, S. (2018). Pigeonholed, peripheral or pioneering? Findings from a national study of Indigenous Australian academics in the disciplines. Studies in Higher Education, 43(9), 1679-1691. https://doi.org/10.1080/03075079.2017.1281240

Australian Bureau of Statistics. (2020, 08/05). Retirement and Retirement Intentions, Australia. Commonwealth of Australia. Retrieved from https:/www.abs.gov.au/statistics/labour/employment-andunemployment/retirement-and-retirement-intentions-australia/latest-release

Battiste, M. (2005). Indigenous Knowledge: Foundations for First Nations. WINHEC: International Journal of Indigenous Education Scholarship, 1. Retrieved from https://journals.uvic.ca/index.php/winhec/article/view/19251

Bazeley, P. (2003). Defining "early career" in research. Higher Education, 45(3), 257-279.

Bazeley, P. (2010). Conceptualising research performance. Studies in Higher Education, 35(8), 889-903. https://doi.org/10.1080/03075070903348404

Behrendt, L., Larkin, S., Griew, R., \& Kelly, P. (2012). Review of higher education access and outcomes for Aboriginal and Torres Strait islander people: Final Report. Retrieved from https://docs.educa tion.gov.au/system/files/doc/other/review_final_report_2012.pdf

Bessarab, D., \& Ng'andu, B. (2010). Yarning about yarning as a legitimate method in Indigenous research. International Journal of Critical Indigenous Studies, 3(1), 37-50. https://doi.org/10.5204/ ijcis.v3i1.57

Brayboy, B. M. J. (2005). Toward a tribal critical race theory in education. Urban Review, 37(5), 425446. https://doi.org/10.1007/s11256-005-0018-y 
Browning, L., Thompson, K., \& Dawson, D. (2014). Developing future research leaders: Designing early career researcher programs to enhance track record. International Journal for Researcher Development, 5(2), 123. https://doi.org/10.1108/IJRD-08-2014-0019

Crome, E., Meyer, L., Bosanquet, A., \& Hughes, L. (2019). Improving engagement in an early career academic setting: Can existing models guide early career academic support strategies? Higher Education Research and Development, 38(4), 717-732. https://doi.org/10.1080/07294360.2019.1576597

Delgado, R., \& Stefancic, J. (1992). Images of the outsider in American law and culture: Can free expression remedy systemic social ills? Cornell Law Review, 77(6), 1258.

Denzin, N. K., \& Lincoln, Y. S. (Eds.). (2018). The Sage handbook of qualitative research (5th ed.). Sage. Department of Social Services. (2019, 19 July). Seniors. Age Pension. Australian Government. Retrieved February 08, 2021, from https://www.dss.gov.au/seniors/benefits-payments/age-pension

Fredericks, B. (2011). Universities are not the safe place we would like to think they are, but they are getting safer': Indigenous women academics in higher education. Journal of Australian Indigenous Issues (1998), 14(1), 41-53.

Gaudry, A., \& Lorenz, D. (2018). Indigenization as inclusion, reconciliation, and decolonization: Navigating the different visions for indigenizing the Canadian Academy. AlterNative: An International Journal of Indigenous Peoples, 14(3), 218-227. https://doi.org/10.1177/1177180118785382

Henry, F., Dua, E., Kobayashi, A., James, C., Li, P., Ramos, H., \& Smith, M. S. (2017). Race, racialization and Indigeneity in Canadian universities. Race Ethnicity and Education, 20(3), 300-314. https://doi.org/10.1080/13613324.2016.1260226

Hutchings, K., Bainbridge, R., Bodle, K., \& Miller, A. (2019). Determinants of attraction, retention and completion for Aboriginal and Torres Strait Islander higher degree research students: a systematic review to inform future research directions. Research in Higher Education, 60(2), 245-272. https:// doi.org/10.1007/s11162-018-9511-5

Jackson, K., \& Bazeley, P. (2019). Qualitative data analysis with NVIVO (3rd ed.). SAGE.

Joseph, T. D., \& Hirshfield, L. E. (2011). "Why don't you get somebody new to do it?" Race and cultural taxation in the academy. Ethnic and Racial Studies, 34(1), 121-141. https://doi.org/10.1080/01419 870.2010 .496489

June, A. W. (2015). The invisible labor of minority professors. The Chronicle of Higher Education, 62(11), A32.

Kidman, J., \& Chu, C. (2017). Scholar outsiders in the neoliberal university: Transgressive academic labour in the whitestream. New Zealand Journal of Educational Studies, 52(1), 7-19. https://doi. org/10.1007/s40841-017-0079-y

Klopper, C. J., \& Power, B. M. (2014). The casual approach to teacher education: What effect does casualisation have for Australian university teaching? The Australian Journal of Teacher Education, 39(4), 101-114. https://doi.org/10.14221/ajte.2014v39n4.1

Ladson-Billings, G. (1998). Just what is critical race theory and what's it doing in a nice field like education? International Journal of Qualitative Studies in Education, 11(1), 7-24. https://doi.org/10. $1080 / 095183998236863$

Laudel, G., \& Gläser, J. (2008). From apprentice to colleague: The metamorphosis of Early Career Researchers. Higher Education, 55(3), 387-406. https://doi.org/10.1007/s10734-007-9063-7

Martin, K. (2008). Please knock before you enter: Aboriginal regulation of outsiders and the implications for researchers. Post Pressed.

Martin, K., \& Mirraboopa, B. (2003). Ways of knowing, being and doing: A theoretical framework and methods for Indigenous and Indigenist re-search. Journal of Australian Studies, 27(76), 203-214. https://doi.org/10.1080/14443050309387838

Mohamed, T., \& Beagan, B. L. (2019). 'Strange faces' in the academy: Experiences of racialized and Indigenous faculty in Canadian universities. Race, Ethnicity and Education, 22(3), 338-354. https:// doi.org/10.1080/13613324.2018.1511532

Moodie, N. (2018). Decolonising Race theory: Place, survivance and sovereignty. In G. Vass, J. Maxwell, S. Rudolph, \& K. N. Gulson (Eds.), The Relationality of Race in Education Research. Local/Global Issues in Education (1st ed., pp. 33-46). Routledge.

Moodie, N., Ewen, S., McLeod, J., \& Platania-Phung, C. (2018). Indigenous graduate research students in Australia: A critical review of the research. Higher Education Research \& Development, 37(4), 805-820. https://doi.org/10.1080/07294360.2018.1440536

Murray, S. A., Kendall, M., Carduff, E., Worth, A., Harris, F. M., Lloyd, A., Cavers, D., Grant, L., \& Sheikh, A. (2009). Use of serial qualitative interviews to understand patients evolving experiences and needs. British Medical Journal: BMJ, 339(7727), 958-960. https://doi.org/10.1136/bmj.b3702 
Nakata, M. (2006). Australian Indigenous Studies: A question of discipline. The Australian Journal of Anthropology, 17(3), 265-275.

Nana, G., Stokes, F., \& Lynn, A. (2010). Academic Workforce Planning: Towards 2020. Report to Universities New Zealand Human Resources Committee Steering Group.

Page, S., \& Asmar, C. (2008). Beneath the teaching iceberg: Exposing the hidden support dimensions of Indigenous academic work. The Australian Journal of Indigenous Education, 37(S1), 109-117. https://doi.org/10.1375/S1326011100000442

Povey, R., \& Trudgett, M. (2019). When camp dogs run over maps: "Proper-way" research in an Aboriginal community in the North-East of Western Australia. Australian Aboriginal Studies, 2019(2), $61-72$.

Rigney, L.-I. (2001). A first perspective of Indigenous Australian participation in science: Framing indigenous research towards Indigenous Australian intellectual sovereignty. Kaurna Higher Education Journal, 7, 1-13.

Robertson, M. J., \& Fyffe, J. (2019). What happens to doctoral supervision when university departments have high levels of precarious academic employment?: An Australian case study. Innovations in Education and Teaching International, 56(5), 652-662. https://doi.org/10.1080/14703297.2018. 1522268

Sawarkar, R., Scherz-Shouval, R., Denzel, M. S., \& Saarikangas, J. (2019). Chaperoning junior faculty: Institutional support and guidance can relieve challenges for early-career group leaders and improve academic performance. EMBO Reports. https://doi.org/10.15252/embr.201847163

Scaffidi, A. K., \& Berman, J. E. (2011). A positive postdoctoral experience is related to quality supervision and career mentoring, collaborations, networking and a nurturing research environment. Higher Education, 62(6), 685-698. https://doi.org/10.1007/s10734-011-9407-1

Silverman, D. (2013). A very short, fairly interesting and reasonably cheap book about qualitatitive research (2nd ed.). Sage.

Staniland, N. A., Harris, C., \& Pringle, J. K. (2019). Fit for whom? Career strategies of Indigenous (Maori) academics. Higher Education, 79(4), 589-604. https://doi.org/10.1007/s10734-019-00425-0

Sutherland, K. A. (2017). Constructions of success in academia: An early career perspective. Studies in Higher Education, 42(4), 1-17. https://doi.org/10.1080/03075079.2015.1072150

Thunig, A., \& Jones, T. (2020). 'Don't make me play house-n***er': Indigenous academic women treated as "black performer" within higher education. Australian Educational Researcher. https://doi.org/ 10.1007/s13384-020-00405-9

Trudgett, M. (2011). Western places, academic spaces and Indigenous faces: Supervising Indigenous Australian postgraduate students. Teaching in Higher Education, 16(4), 389-399. https://doi.org/10. 1080/13562517.2011.560376

Trudgett, M., Page, S., \& Harrison, N. (2016). Brilliant minds: A snapshot of successful Indigenous Australian doctoral students. The Australian Journal of Indigenous Education, 45(1), 70-79. https://doi. org/10.1017/jie.2016.8

Universities Australia. (2020). Indigenous Strategy Annual Report.

Publisher's Note Springer Nature remains neutral with regard to jurisdictional claims in published maps and institutional affiliations.

Michelle Lea Locke is a proud Dharug woman, and currently a Postdoctoral Research Fellow with Deputy Vice-Chancellor, Indigenous Leadership at Western Sydney University. In 2018, she received the Australian Association for Research in Education's Aboriginal and Torres Strait Islander Postgraduate Student Researcher award for her conference paper, Wirrawi Bubuwul-Aboriginal Women Strong. Michelle's thesis, Yanna Jannawi: Centering Indigenous Ways of Knowing in Early Education and Care Services was conferred in January 2021 through the Centre for Advancement of Indigenous Knowledges at the University of Technology Sydney. This thesis examines Indigenous perspectives on culturally relevant and respectful approaches to the inclusion of Indigenous Ways of Knowing in mainstream early education and care services.

Michelle Trudgett is an Indigenous scholar from the Wiradjuri Nation in New South Wales. Michelle holds the position Deputy Vice-Chancellor, Indigenous Leadership at Western Sydney University. Prior 
to this appointment, she served as the Inaugural Director of the Centre for the Advancement of Indigenous Knowledges at the University of Technology Sydney and was previously the Head of Indigenous Studies at Macquarie University. In recognition for her contributions to higher education, Michelle has received several awards including the highly prestigious National NAIDOC Scholar of the Year Award, the Neville Bonner Award for Teaching Excellence, and the University of New England Distinguished Alumni Award.

Susan Page is an Aboriginal academic and is Director of Indigenous Learning and Teaching at University of Western Sydney. Susan recently led a university-wide Indigenous graduate attribute project and was previously Head of the Department of Indigenous Studies at Macquarie University (2008-2012). Her research focuses on Aboriginal and Torres Strait Islander peoples' experience of learning and academic work in Higher Education and student learning in Indigenous Studies. Susan has been the recipient of a number of competitive research grants, and is well published in the area of Indigenous Higher Education. In 2018 she led the team (Page, Trudgett \& Bodkin-Andrews) which was awarded a national teaching excellence award, the Neville Bonner Award for Indigenous Education. 